DEPARTMENT OF COMMERCE BUREAU OF STANDARDS

George K. Burgess, Director

TECHNOLOGIC PAPERS OF THE BUREAU OF STANDARDS, No. 304

[Part of Vol. 20]

\title{
A METHOD FOR TESTING GAS APPLIANCES TO DETERMINE THEIR SAFETY FROM PRODUCING CARBON MONOXIDE
}

BY

E. R. WEAVER, Chemist

J. H. EISEMAN, Associate Physicist

G. B. SHAWN, Assistant Physicist

Bureau of Slandards

January 11, 1926

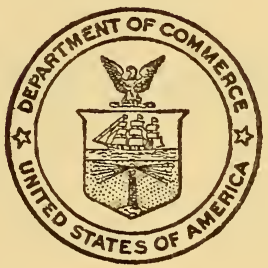

PRICE 10 CENTS

\$1.25 PER VOLUME ON SUBSCRIPTION

Sold only by the Superintendent of Documents, Government Printing Office Washington, D.C.

WASHINGTON

GOVERNMENT PRINTINC OFFICE 



\title{
A METHOD FOR TESTING GAS APPLIANCES TO DETER- MINE THEIR SAFETY FROM PRODUCING CARBON MONOXIDE
}

\author{
By E. R. Weaver, J. H. Eiseman, and G. B. Shawn
}

ABSTRACT

In recent years there has been an increasing number of reports of more or less serious injury from carbon monoxide liberated from gas appliances. Efforts are being made by several organizations both within and outside the gas industry to remove the causes of this trouble by determining what appliances are safe and encouraging the use of only those which are not subject to this hazard.

In this paper the causes which result in the liberation of carbon monoxide from appliances are briefly discussed, together with the character of the tests which must be applied to determine the relative safety of different appliances in use.

Recently developed methods for testing appliances and clearly representing the characteristics which are important to safety are described. The results of tests upon numerous appliances are given in graphic form, both to illustrate the application and value of the testing methods, to show the range of hazard in existing appliances, and to indicate what may reasonably be expected of a good appliance in service. It is shown that all types of appliances commonly usedranges, water heaters, radiant room heaters, etc.-can readily be made safe from the carbon monoxide hazard, but that there is no certain way, except a laboratory test, by which even an experienced person may judge whether an appliance is or is not operating safely.

\section{CONTENTS}

I. Introduction $\ldots \ldots \ldots$

II. Conditions which make the testing of appliances necessary _.

III. Causes of carbon monoxide production by gas appliances_._._.

IV. Type of tests needed. 130

V. Apparatus used in testing 134

VI. Method of test

1. Determination of flash-back, blow-off, and yellow-tip

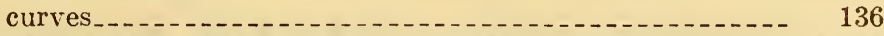

2. Determination of the limit of complete combustion._. 137

3. Determination of normal injection curve... 13 ?

VII. Typical results of appliance tests

VIII. Summary

\section{INTRODUCTION}

Several of the larger gas companies have been for several years systematically testing appliances for use in the territories which they serve, and much progress in the development of appliances has 
resulted from their efforts. The Bureau of Mines, the Bureau of Standards, two or three university laboratories, several appliance manufacturers, and various other organizations have likewise been engaged in the study and testing of appliances. In spite of the efforts which have been made by these organizations there has been an apparent increase in the amount of carbon monoxide poisoning which has occurred in connection with the use of gas, although it is possible that the trouble has not increased, but only that its source has come to be more generally recognized.

For reasons which will be pointed out in this paper the problem of providing safe appliances is one which can not well be solved by merely local action. As this fact became apparent, plans were made for cooperation among those most interested, especially the American Gas Association, the Natural Gas Association of America, and the Government bureaus, with the result that an appliance testing laboratory is now being established at Clereland, Ohio, by the American Gas Association. This laboratory is intended to serve both the natural gas and the manufactured gas industries. To the Bureau of Standards has been assigned the primary responsibility for the basic researches necessary on the utilization of gas, especially upon the development of test methods. It is the purpose of this paper to describe the methods which have been thus far dereloped to determine the margin of safety of an appliance used with a certain gas supply.

In order that the reasons for the various tests may be clearly understood, a general statement will be given of the conditions which make appliance testing necessary and the requirements which the test methods must meet in order that they shall be practicable and significant. The testing methods will then be briefly described, and the results of tests upon a number of appliances will be presented and discussed in detail. The results of tests are given not alone to illustrate the character and significance of the test methods, but to show something of the varied characteristics of the appliances now manufactured, and thereby to provide an indication as to what may reasonably be expected of a good appliance in service.

\section{CONDITIONS WHICH MAKE THE TESTING OF APPLI- ANCES NECESSARY}

From the information which has reached the Bureau of Standards in the past two or three years it appears that, although the use of gas provides one of our safest as well as most convenient means of obtaining heat for household use, a certain amount of carbon monoxide poisoning has occurred in connection with the use of domestic gas appliances. The injury caused has ranged from slight periodic headaches to death. The almost universal use of gas in cities makes 
the aggregate number of such cases a matter for serious concern. The causes which produce this condition exist very generally throughout the United States in the territories served with both natural and manufactured gases. The appliances which cause many minor cases, at least, can not be regarded as defective or antiquated; nor are they operated under abnormal conditions. On the contrary, many of them are modern, recently installed, and normally adjusted.

It may be briefly stated that there is for every appliance a maximum, and for some appliances a minimum, quantity of gas which can be burned completely and therefore safely, and that this quantity varies with the pressure and composition of the gas supply and the adjustment of the appliance.

There are in the United States about 2,000 gas companies supplying manufactured and natural gas as public utilities. The heating ralue of the gas supplied raries from 340 to 1,400 B.t. u. per cubic foot, and perhaps more. Pressures at the consumers' appliances differ from not more than 0.5 inch to at least 50 inches of water column. The variation of pressure which sometimes occurs in a given system ranges from less than twice the minimum to 16 times the minimum.

Since blending of natural gas with manufactured gas, or other treatment to increase the supply, has been resorted to in the naturalgas regions, there is represented in the whole country a practically continuous range of heating values and pressures from one extreme to the other. So far as the bureau is informed no manufacturer of appliances has any accurate way of determining the limiting conditions of gas supply under which each of his models will operate satisfactorily; and no consumer has any way of assuring himself that his appliance is adapted to his serrice conditions. Only a few of the larger gas companies hare any way of determining what appliances can be used safely under the conditions which they maintain, and even these hare no way of controlling the sale by other agencies of unsuitable appliances within their telritory, although they often receive the blame for the trouble caused when anything goes wrong with such appliances. Generally speaking, when a gas company desires to change the conditions of its service, either by a change of pressure or of the composition of the gas, it has no way of knowing how many or which of the appliances in service will be unsuitable for the new condition of supply.

It seems erident that the only way of remedying this situation is to determine in a systematic manner the conditions of gas supply for which every appliance offered for sale is suitable; to provide the manufacturer of the appliance with a list of the territories in which such conditions of gas supply prerail; and to provide each gas company with a list of the appliances suitable for use under its local conditions. The systematic supplying of this information to the 
appliance industry, on the one hand, and the gas industry, on the other, is the thing most needed, but it seems possible to accomplish other desirable purposes at the same time.

The thorough testing to which an appliance must be subjected in order to determine under what conditions it can be used with entire safety will indicate in most cases what changes will be necessary in order to make the appliance suitable for the desired market. These changes should be freely suggested to the manufacturer with the ultimate result that the product of a competent manufacturer will not be eliminated from the market but will be brought up to the standard which can be marketed.

A great service will also be rendered to the public if it is possible to so designate an appliance that the purchaser will know at once that a competent authority has determined whether it is or is not suitable for the consumer's particular conditions of gas service. It is probable that if the public should become aware of the fact that appliances could be obtained which had been tested for safe and satisfactory performance the demand for such appliances would force out of the market those which did not meet the requirement.

\section{CAUSES OF CARBON MONOXIDE PRODUCTION BY GAS APPLIANCES}

The liberation of carbon monoxide by gas appliances may be classified under three headings: (1) That caused by accidents over which the manufacturer or user has no control, (2) that produced by conditions which are noticeably wrong and are generally corrected or made the subject of complaint by the user, and (3) that produced by appliances which to the untrained observer appear to be operating normally. The third is the one which is apparently the principal cause of trouble and is the most difficult to eliminate.

Under the first heading are accidental turning on of stopcocks, extinction of the flame by drafts, leaks, etc.

The second class includes flash back, flames blowing from the ports, yellow flames where the appliance is designed for blue, and all other conditions that are noticeably wrong. The majority of the burners used in domestic appliances are blue-flame burners and are so designed that a portion of the air necessary for complete combustion mixes with the gas before reaching the burner ports; this is called "primary" air. The additional air needed is secured from the atmosphere surrounding the flames and is termed "secondary" air. As the amount of primary air which mixes with a given amount of gas is increased a point is reached where the flame either blows away from the ports or flashes back into the burner, depending upon the gas rate and the design of the burner. Either of these conditions is 
usually dangerous and represents the ratio of primary air to gas above which the appliance can not be satisfactorily operated.

As the amount of primary air is decreased, a condition is reached where the flame begins to show yellow. In most appliances this is to be avoided because carbon is deposited on the metal or material surrounding the flame; and, although the yellow flame is not necessarily a sign of carbon monoxide production, its use is not good practice because it lowers the heating efficiency. (There are some appliances designed to burn with a yellow flame, but in these the flame does not impinge on any solid surface, and as it burns freely in the surrounding air the above objection does not apply.)

The third class of conditions which result in the liberation of carbon monoxide includes the use of appliances in which the flame is stable and which do not deposit carbon, but in which combustion is nerertheless incomplete. The following brief discussion indicates the principal factors which produce such conditions.

The burning of gas is a chemical reaction between the gas and the oxygen of the air, which will take place only at high temperatures. When the flame has an unrestricted supply of air and it does not come in contact with surrounding objects, combustion is complete. This is true whether or not air is mixed with the gas before it issues from the burner ports. If, however, the access of air to the flame is so restricted that the quantity of oxygen which mixes with the gas stream before it is cooled below the reacting temperature is insufficient to combine with all of the gas, combustion is incomplete and carbon monoxide is produced.

The supply of secondary air to most appliances is exactly like the draft in a chimney and results from the same cause, which is the upward displacement of the heated gases by the surrounding air, which is cold and therefore relatively heary. When considering secondary air three causes of failure to meet the requirements for complete combustion may be distinguished: (1) The draft through an appliance is not great enough to supply the amount of oxygen chemically required for complete combustion. (2) The total amount of secondary air circulating through the appliance may be adequate, but its distribution and direction of flow and the arrangement of burner ports are such that some of the flames do not receive their share. (3) The secondary air may be adequate and well distributed, but the combustion space is too small to permit complete combustion before the gases are cooled below the reacting temperature. In most appliances an excessive supply of secondary air unfavorably affects the thermal efficiency, hence appliances should be, and usually are, designed to take as small a quantity of secondary air as possible without affecting the completeness of combustion. When the effort to secure this efficiency is carried too far and the supply of secondary 
air, or the space allowed for combustion, is too limited for the quantity of gas burned, one or more of these three dangerous conditions is encountered.

The greater the proportion of the air needed for complete combustion that is injected as primary air the smaller the quantity of secondary air required, with a consequent minimizing of the chances of smothering the flame. Primary air is much more effective than secondary in assuring complete combustion because it is mixed with the gas from the start and has an opportunity to react during the whole time from ignition to final cooling below the reacting temperature, and also, in some cases, because it reduces the volume of the flame. Provision for primary air is therefore one of the most important characteristics of any particular design.

\section{TYPE OF TESTS NEEDED}

In order for methods of test to accomplish the desired results they must fulfill sereral requirements. First, they must be easy of application to all types of gas appliances. Second, the results should be of such a nature as to permit an accurate determination of the conditions under which the appliance will fail to give satisfactory service on any one gas supply. Third, from the results obtained with one gas supply or a reasonable number of gases it should be possible to judge the operation of a particular appliance under all other gas service conditions. Fourth, the complete testing of an appliance should be fairly rapid. Fifth, in order for the tests to be productive of the greatest good, an interpretation of the cause or causes of failure should be possible, thus enabling the manufacturer of a poor appliance to correct his design and make the appliance satisfactory for the service it is intended to render.

The tests described in this paper hare been dereloped to meet the requirements outlined, but they cover only a portion of the necessary field. This paper deals only with tests which show under what conditions combustion is satisfactory from the standpoint of safety and does not include any consideration of efficiency or other requirements for a good appliance. The paper is also limited to tests with a single gas; the necessary study of the effect of changing the composition of the gas supply upon the performance of the appliance awaits facilities which are now being provided.

In explaining the reasons for the tests described it may be helpful to consider them first from the standpoint of the user of an appliance, then from that of the manufacturer.

Generally the user of an appliance or the one who installs and adjusts it has opportunity to control only three conditions: (1) The size of the orifice, which is usually either adjustable or easily replaceable; (2) the pressure of the gas at the orifice, which is subject to control 
by the supply cock or a pressure regulator; and (3) the primary air opening. Two of these adjustments affect the amount of gas burned; all three affect the amount of primary air. All other conditions are usually determined by the construction of the appliance. So far as the user is concerned we may, therefore, reduce the three variable conditions to two-the amount of gas burned and the amount of primary air injected. To determine completely the satisfactory operating range of any appliance (with a gas of definite composition) requires a knowledge for each gas rate of the amount of primary air which will (1) permit the complete combustion of the gas,(2) prevent the deposition of carbon by a yellow flame, (3) cause the flame to flash back into the mixing tube, or (4) cause the flames to blow

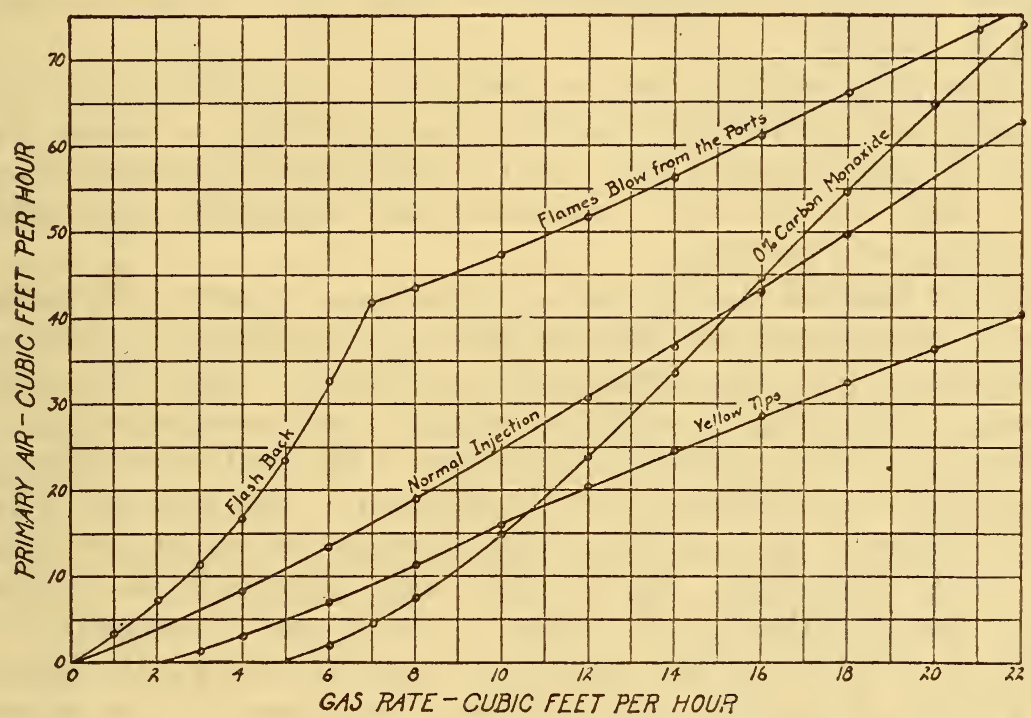

FIG. 1.-Curves representing in the simplest way the limiting conditions of safe operation of an appliance

away from the ports. These facts when determined may all be readily represented upon a single diagram, the coordinates of which correspond to the amount of gas burned and the amount of air injected. On the same diagram may be represented the effect of each change of the adjustments of orifice, pressure, and air shutter. We thus have in a single diagram a complete representation of all important facts regarding the appliance.

Figure 1 shows such a set of tests plotted in this manner. The significance of the various curves may be seen from the following examples: With gas burning at the rate of 12 cubic feet per hour, the appliance would usually be adjusted to inject about 30 cubic feet of primary air per hour as shown by the curve marked "normal injection." When gas is used at this rate, an air injection of 51.5 cubic $61645^{\circ}-26-2$ 
feet per hour would cause the flames to blow from the ports (as shown by the curre marked "Flames blow from the ports"). If, on the other hand, the air injection had been less than 24 cubic feet per hour combustion would have been incomplete; and had there been less than 20 cubic feet of primary air per hour the flames would have shown yellow tips. These facts are shown by the curves marked "0 per cent carbon monoxide" and "yellow tips," respectively. The appliance can not be made to flash back when burning gas at this rate, but with gas burning at a rate of 6 cubic feet per hour any amount of primary air greater than 32.5 cubic feet per hour will cause the flame to flash back into the burner. If while burning gas at this rate the appliance is so adjusted that only 5 cubic feet of air per hour is injected, the flame will deposit carbon, but no carbon monoxide will be released.

From these curves it can be seen that as normally operated no trouble was experienced from flash back, blowing, or yellow tips over the entire range of test; but if the gas rate was increased above 15.5 cubic feet per hour, combustion was incomplete and carbon monoxide was produced.

Such a diagram at once gives a great amount of useful information to the designer who may wish to improre the appliance, and the information is, in a sense, already analyzed for him. None of the many changes which may be made in the gas or air passages before the ports are reached can affect the position of the limits of satisfactory operation as represented upon the diagram. They can only affect the rolumes of gas and air passing through the burner, and these are easily determined. On the other hand, changes in the combustion space, whether of size, shape, or circulation of secondary air, can only affect the limits of satisfactory operation and not the amount of primary air injected. The problem of the designer is thus divided into two very much simplified parts.

As stated above, the work of this bureau so far has been with one quality of gas only, namely, carburetted water gas of $600 \mathrm{~B}$. t. u. per cubic foot. The method of test described below has proved very satisfactory in determining the operation of an appliance with the service conditions found in Washington, D. C. It is fairly rapid considering the number of facts determined, and from the results of the tests a knowledge of the changes necessary to improve a poor appliance can be readily obtained. This same method would be just as useful in any other locality.

Whether it is going to be possible to estimate the satisfactory operating range of an appliance on all qualities of gas from a test on one quality only is a question which is still undetermined. This will be the subject of additional research in the near future and the results obtained will be published in a later report. 
The method used in Figure 1 for plotting the test data is well suited to represent results obtained with any gas supply which varies little in composition, for when the amount of air required to burn the gas is practically constant and the gas rate is unchanged the same rate of primary air supply will always cause the same conditions of combustion. However, the ultimate goal of the tests made with one gas is frequently the determination of the range of safe and satisfactory operation of the appliance with every gas supply, and one can not readily judge from such a figure as this what will be the results obtained when using the same appliance with a gas of different composition. Obviously, the flame resulting from a mixture of 1 cubic foot of 400 B. t. u. gas and 2 cubic feet of air, for example, is not identical in appearance, in the amount of secondary air required to complete the combustion, or in other respects, with one obtained from a mixture of air in the same proportion with a gas of $1,000 \mathrm{~B}$. t. u. per cubic foot. We must take into account not only these widely separated cases, but many others occupving the whole range of heating values.

Both the heating ralue of a gas and the amount of air required to burn a cubic foot of it vary with its composition. As the total air requirement varies, the type of flame and the amount of secondary air required (when the appliance is supplied with a fixed amount of primary air) also change; hence, the volume of the primary air entrained will not serve as a basis of comparison of the results obtained with different gases. The type of flame can be kept more nearly the same for gases of different composition if the primary air supplied with each gas constitutes the same percentage of the total air required to completely burn the gas. Since conditions of combustion are largely dependent on the type of flame, which is, in turn, controlled by the primary air supply, all primary air values are plotted in the curves as percentages of the total air requirement.

In practically all domestic appliances satisfactory service calls for a certain rate of liberation of heat. The heat produced in a given period is the product of the volume of gas burned and its heating value per cubic foot. The service rendered is measured directly by this product and not by the volume of gas burned. The gas rate is plotted in the remaining figures, therefore, as the rate of supply of heat units. The designation of the gas rate in terms of heat units has another advantage. The amount of air required to completely burn a cubic foot of any of the manufactured or natural gases usually encountered is very nearly in proportion to the heating value. Hence, the same amount of heat from different gases represents about the same air requirement, as well as the same thermal conditions in the appliance and the same effective service when used. The use of these coordinates in plotting the test results giren in this 
paper, therefore, makes possible a direct comparison between them and similar data obtained by the use of other gases with the same appliance. The type of flame, operating limits, completeness of combustion, and the quality of the service represented by the diagrams should be nearly, though not quite, the same for different gases.

\section{APPARATUS USED IN TESTING}

The apparatus formerly used by the bureau in determining air-gas ratio, as well as that for testing combustion products, is described in two previous bureau publications, ${ }^{1}$ which also contain the representation of combustion data by coordinates showing quantities of gas and primary air. Tests made with the apparatus formerly used,

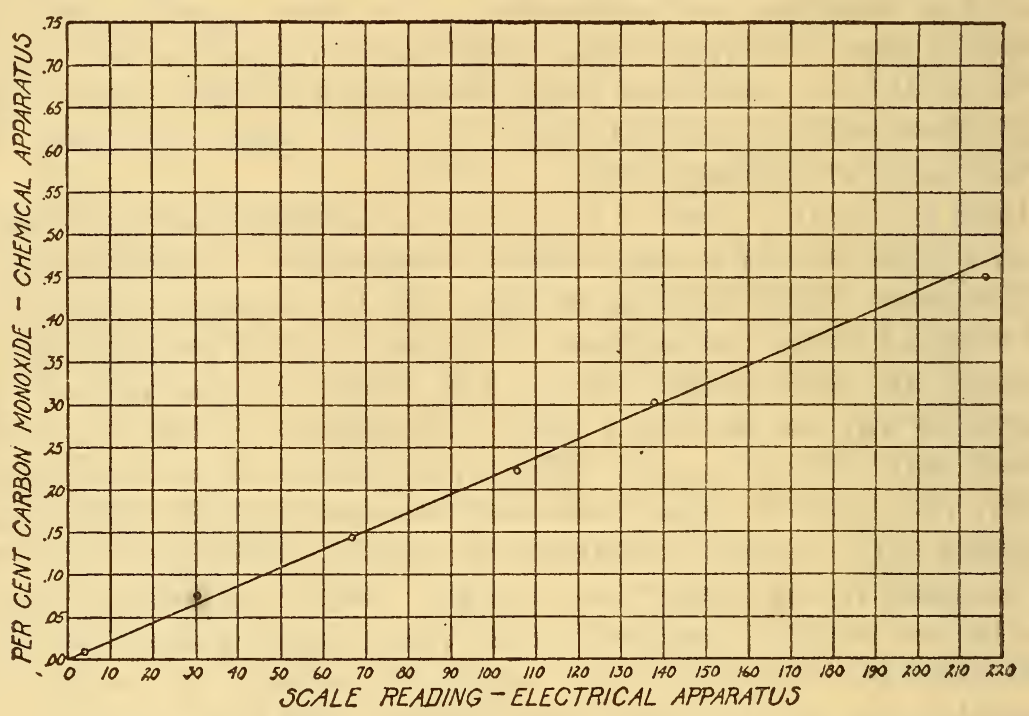

Fig. 2.-Calibration curve of electrical carbon monoxide indicator

however, require an unreasonable length of time for the number of tests necessary to completely represent the characteristics of an appliance. Accordingly, electrical apparatus has been developed to replace both the apparatus formerly used to determine air-gas ratio and the chemical apparatus used for the determination of carbon monoxide and carbon dioxide in the products of combustion. Determinations can be made by the electrical methods in a much shorter time, while their accuracy compares favorably with that of the methods formerly used. A comparison of the two types of apparatus is especially interesting in the determination of combustibles in the

1 B. S. Tech. Paper No. 193, Design of Atmospheric Gas Burners, by Walter M. Berry, I. V. Brumbaugh, G. F. Moulton, and G. B. Shawn; and B. S. Tech. Paper No. 222, Relative Usefulness of Gases of Different Heating Value and Adjustments of Burners for Changes in Heating Value and Specific Gravity, by Walter M. Berry, I. V. Brumbaugh, J. H. Eiseman, G. F. Moulton, and G. B. Shawn. 
combustion products. The time required for a test with the chemical apparatus is about 30 minutes, while the electrical method requires only about 6 minutes. Figure 2 shows the calibration curve of the electrical apparatus for carbon monoxide obtained by comparison with the chemical apparatus when a slightly smothered blue flame was the source of carbon monoxide. The results of tests which follow are in no way dependent upon the analytical methods employed. They would hare been the same had any other accurate methods been used. For this reason a description of the analytical methods will be reserved for a later paper.

\section{METHOD OF TEST}

The tests made on an appliance can be grouped under two headings-_"forced" and "normal." The forced tests are those made to determine the limits of operation of the appliance, and the normal

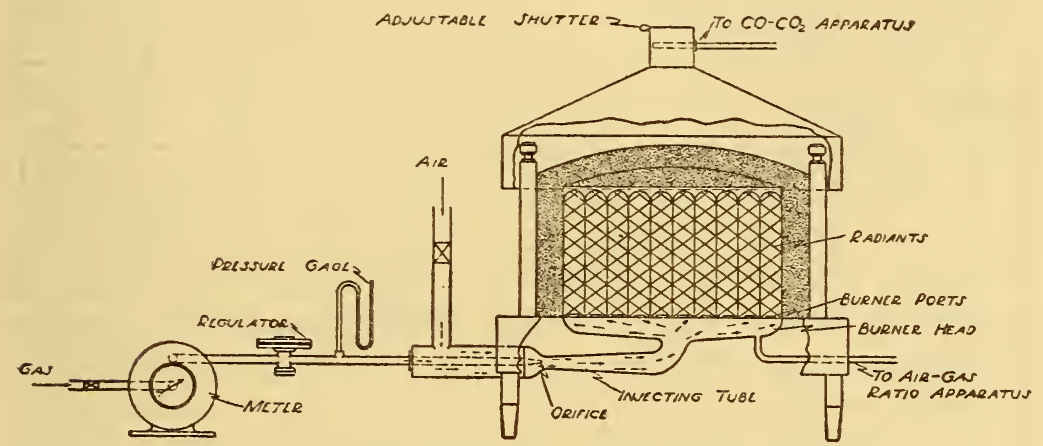

Fig. 3.-Diagram of apparatus used to test appliances

tests are those which are made with the appliance operating as it would in actual use. A comparison of the results of these two groups of tests shows whether or not the appliance will operate satisfactorily in practice. The forced tests will be described first.

The appliance to be tested is connected to a supply of gas and air, which can be raried at will, and the air is forced into the injecting tube under pressure instead of being drawn into it from the room by the flow of the gas. A sampling tube from the burner head to the air-gas ratio apparatus provides means for determining the proportions of air and gas for every setting, and another similar tube conveys a sample of the products of combustion from a hood above the appliance to the carbon monoxide and carbon dioxide apparatus for analysis (see fig. 3). With this arrangement it is possible to quickly produce any desired mixture of primary air and gas, to accurately determine their proportions, and to determine the percentages of carbon monoxide and carbon dioxide in the products of combustion from each setting. 


\section{DETERMINATION OF FLASH-BACK, BLOW-OFF, AND YELLOW-TIP CURVES}

With the appliance installed for test as shown in Figure 3 and burning gas at a constant rate the primary air is increased until the flames either blow from the ports or flash back into the burner. When this condition is reached, a sample of the mixture of air and gas within the burner is drawn off and the relative proportions determined. The primary air is now decreased until yellow begins to appear in the flame, when a sample of the mixture within the burner is again drawn and analyzed. The gas rate is now changed and the same procedure

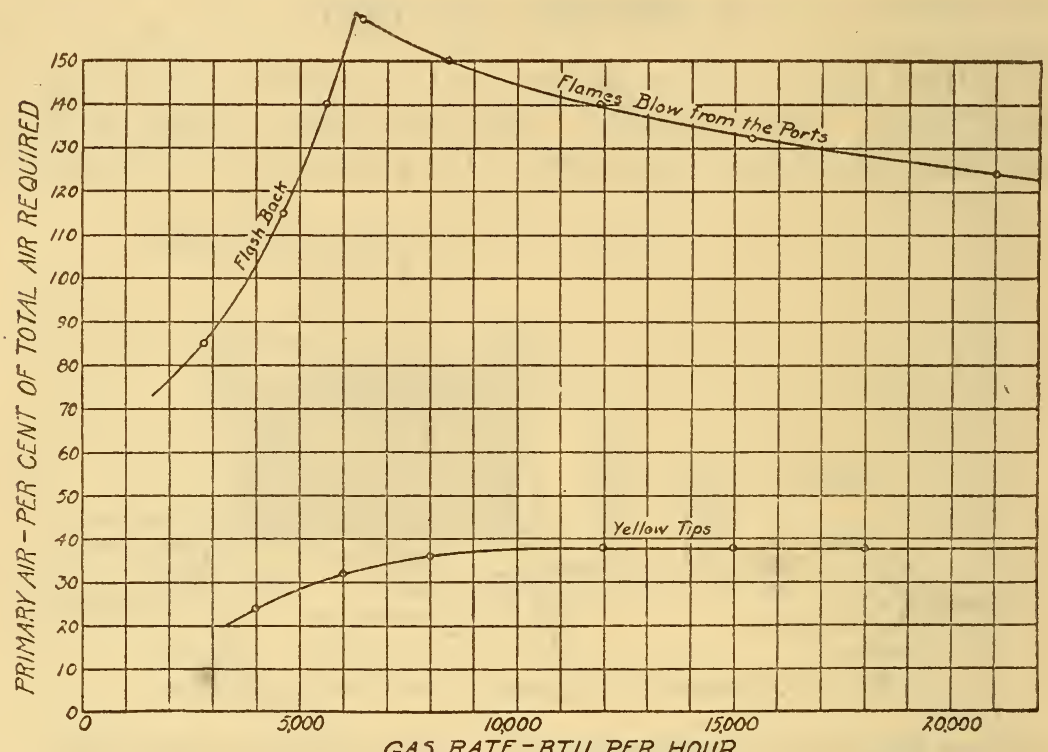

FIG. 4.-The limiting conditions of operation of an appliance which are easily recognized when encountered

repeated. This is done until a series of tests has been made covering the entire range of gas rates the appliance is likely to encounter. These points are then plotted as shown in Figure 4, and the curves obtained are labeled "flash back," "flames blow from the ports," and "yellow tips" according to the condition represented.

Too much reliance should not be placed upon the flash-back curve obtained in this manner because it does not represent, with as much accuracy as is desirable, the danger of flash back in actual service. The reason for the unsatisfactory character of the flash-back tests is as follows:

Flash back occurs when the velocity of flame propagation in the mixture of air and gas leaving the burner exceeds the velocity of flow 
through the port. ${ }^{2}$ In order to obtain consistent results, the composition of the mixture and the rate of flow through the ports must be changed very slowly while the burner is shielded from any condition which would momentarily check the flow. In practice, fluctuations in the gas pressure, a sudden closing of the stop cock, or drafts of air blowing across the burner cause fluctuations in the velocity through the port, and render the appliance much more liable to flash back than the curre might be thought to indicate. Additional research is now being planned to derelop a method of testing for flash back which will more closely represent the danger from this hazard which occurs in practice.

\section{DETERMINATION OF THE LIMIT OF COMPLETE COMBUSTION}

The "0 per cent carbon monoxide" curve is one which shows the relationship between the amount of gas burned and the smallest quantity of primary air which will result in complete combustion. This curve is obtained as follows: The appliance is connected to a forced air supply as described above and the gas is burned at a constant rate. The first test is made with only a small amount of primary air, and a sample of the products of combustion is collected and analyzed for both carbon monoxide and carbon dioxide. At the same time the percentage of air and gas in the mixture within the burner head is determined. The primary air is now increased and the same procedure repeated. This method of increasing the primary air and analyzing the products of combustion is continued until a setting is made from which very little, if any, carbon monoxide is formed. Other determinations at various gas rates are made in the same manner. The percentage of $\mathrm{CO}$ is reduced to an air-free basis by computation from the percentage of $\mathrm{CO}_{2}$ in the sample; this is done to correct for the amount of excess air drawn in at the time of sampling. The results are plotted as shown in Figure 5, all curves being extrapolated to the 0 per cent carbon monoxide line.

From this chart the amount of primary air necessary to produce complete combustion for any of the gas rates used can be readily determined. For example, in the case of the appliance represented by Figure 5, it was necessary, when burning gas at a rate of 14,000 B. t. u. per hour, to inject 66.6 per cent of the air necessary for complete combustion in order to avoid production of carbon monoxide. The points where the curres representing various rates intersect the 0 per cent carbon monoxide line are replotted using the same co-

2 The relocity of flame propoagation is dependent upon the diameter of the channel and the temperature of its walls as well as upon the composition and initial temperature of the gas mixture. The velocity through the ports which will prevent flash back can not, therefore, be accurateiy predicted from the velocity of the flame in a large volume of the air-gas mixture. 
ordinates as used for the flash-back, blow-off, and yellow-tip curves. The curve thus produced is called the " 0 per cent carbon monoxide" curve.

Curves representing other amounts of carbon monoxide, such as $0.1,0.2$ per cent, etc., can also be drawn by plotting in the same manner the points from the curves of Figure 5, which correspond to

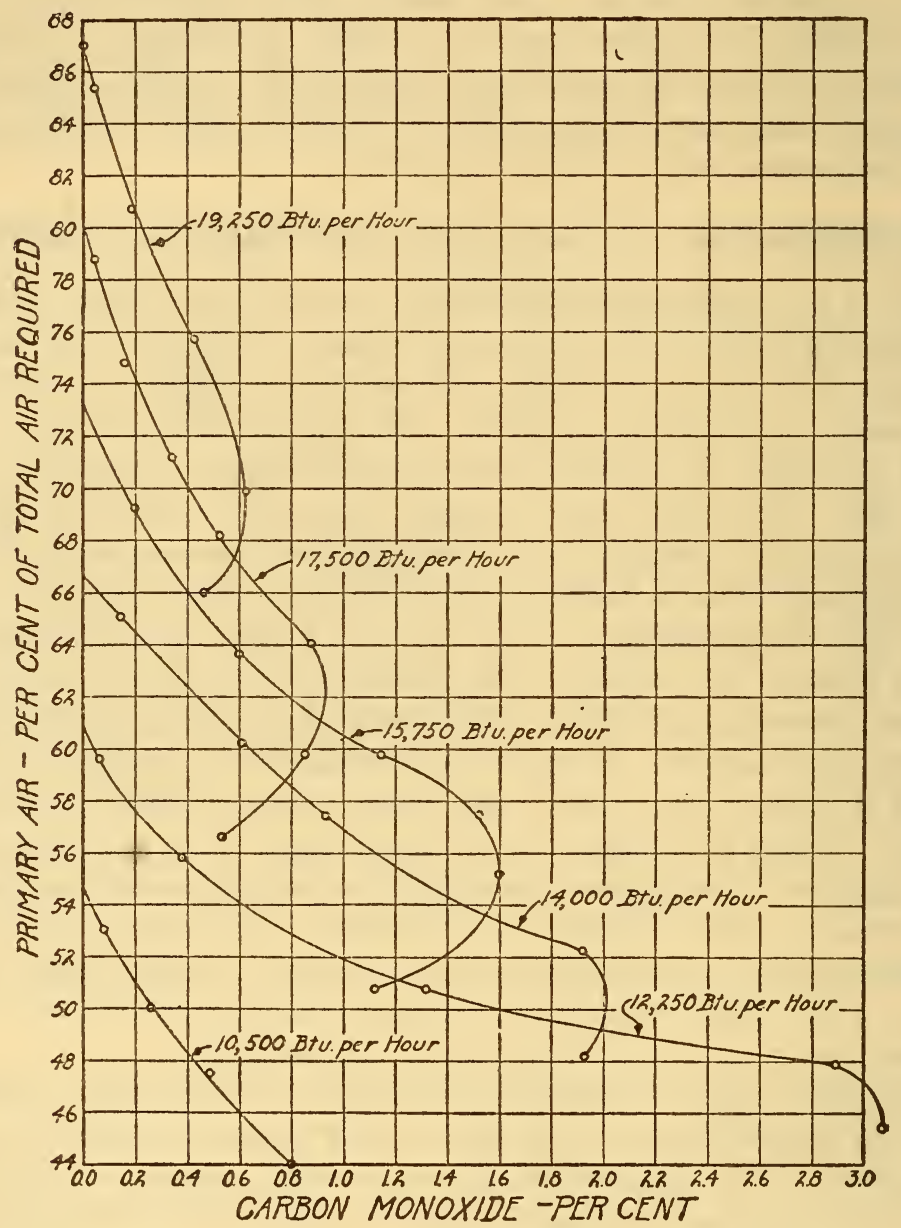

Fig. 5.-Typical observations of carbon monoxide produced by a radiant heater

these values. The 0 per cent carbon monoxide curve as well as curves showing $0.1,0.2,0.5$, and 1.0 per cent are shown in Figure 6 .

Any condition of operation represented by a point below the 0 per cent $\mathrm{CO}$ curre produces carbon monoxide, while all conditions above the curve represent complete combustion. The curves shown on this chart represent the limits of operation beyond which the heater 
can not operate satisfactorily. It remains necessary to determine only the normal operation of the appliance and show this in a curre plotted on the same chart.

\section{DETERMINATION OF NORMAL INJECTION CURVE}

For the determination of this curve the appliance is connected to a source of gas supply only, the primary air entering the air mixer from the room as it would in ordinary use. The orifice used is the one supplied with the appliance by the manufacturer. When an air shutter is supplied; it is left wide open whenerer possible; but when this results in the flames blowing from the ports, or flashing back into

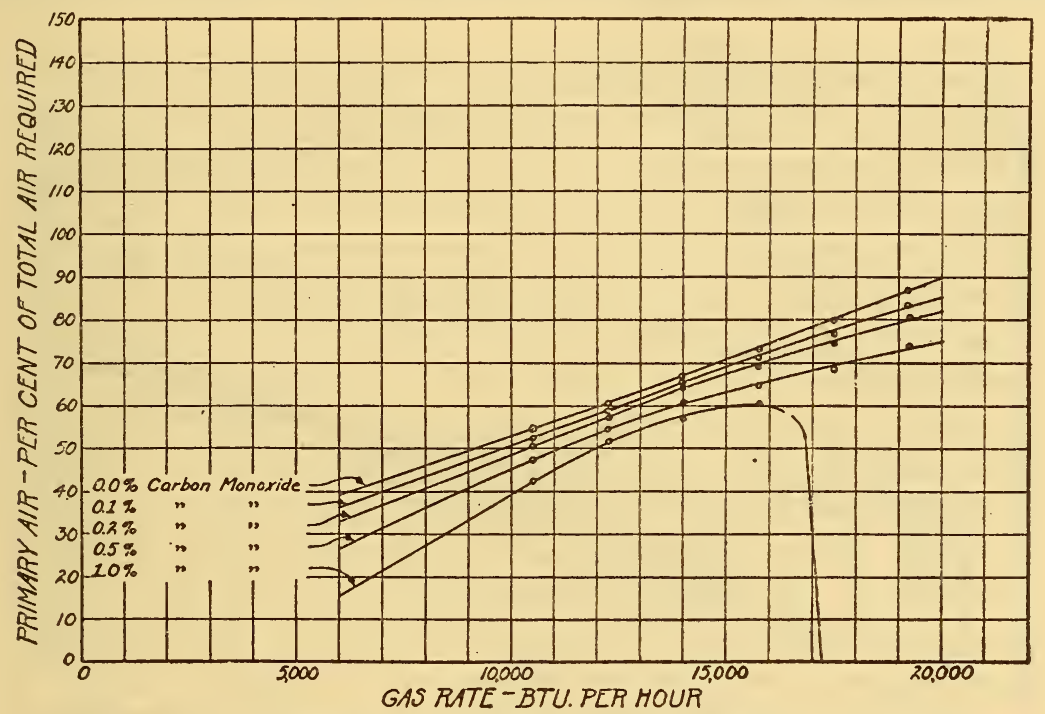

Fig. 6.-Typical curves showing the conditions under which various amounts of carbon monoxide are formed

the burner when the gas is suddenly turned off, the shutter is closed until these conditions are eliminated. The only difference between the installation of the appliance for this test and the way it would be installed in the home is the connection of the sampling tube from the burner head to the air-gas ratio apparatus.

The appliance is then operated at a number of different gas-line pressures to cover the entire range of pressure variation in the locality of test. The percentages of air and gas within the burner head and the gas rate are determined for each setting. These points are plotted on the same chart with the curves showing the limits of operation, and the curve connecting them is labeled "normal injection." The points labeled " 1 "," " 2 "," etc., on the normal injection curve represent the gas pressures, in inches of water at the orifice, 
required to give the gas rate indicated. The complete set of curves for the appliance is shown in Figure 7 .

\section{TYPICAL RESULTS OF APPLIANCE TESTS}

In order to determine the applicability of these tests, a number of various types of appliances were tested in the manner described. The curves obtained are shown in Figures 7 to 24; these figures will require little explanation beyond that already given, but some of their more interesting features may be pointed out with advantage. It is the purpose of these figures not only to illustrate the way in which the test methods indicate the faults of an appliance, but it is

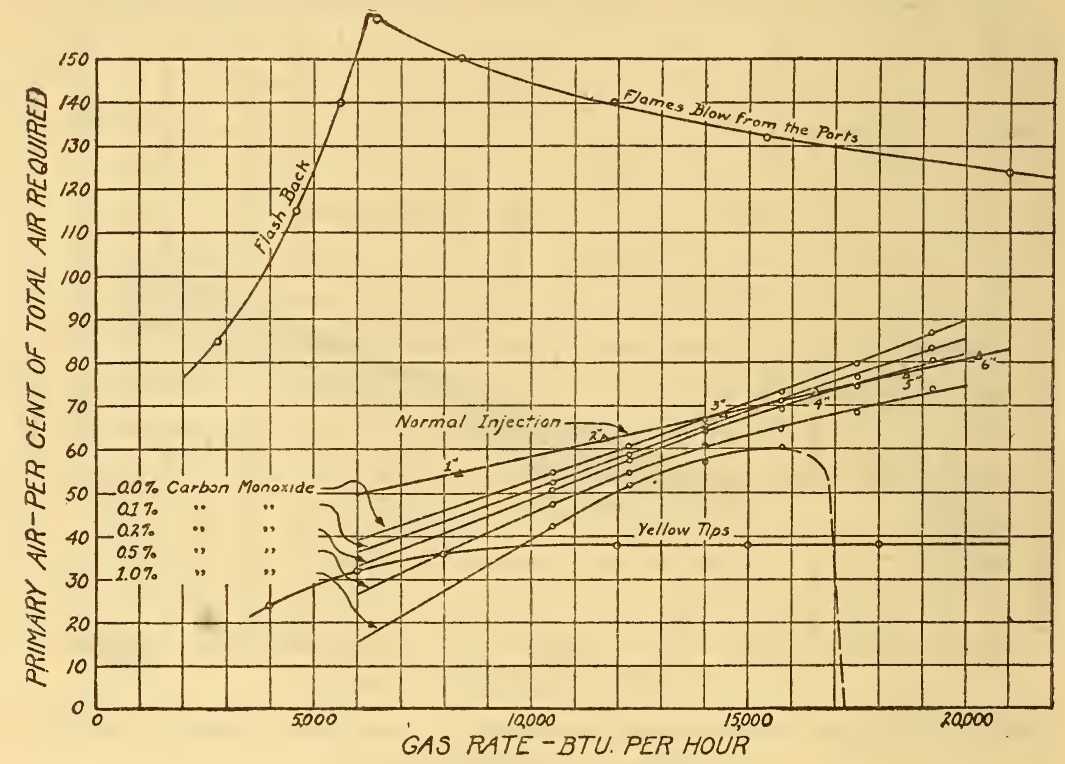

Fig. 7.-Completed diagram representing the performance of radiant heater No. 1

even more important to show something of the range of characteristics of appliances now manufactured and to indicate what performance may reasonably be expected of a good appliance.

Figures 7 to 15 represent radiant heaters, of which those represented by 8 to 12 are safe for use under the conditions of gas supply existing in Washington, while those represented by Figures 7, 13, 14, and 15 are not. In the case of the appliance represented by Figure 7, there is a very wide margin between conditions which would cause incomplete combustion and those which would result in flash back or blowing out of the flames. The normal injection curve in the figure is that obtained with the orifice supplied at the time of test by the manufacturer for use in Washington. If a smaller orifice is used, 
a higher ratio of primary air to gas is obtained and the appliance is safe. If, however, the manufacturer of this appliance does not wish to reduce the amount of gas delivered at a certain pressure, combustion can be made complete either by a modification of the burner which will increase the primary air injection, or by so changing the size or form of the radiant that the flames receive a better supply of secondary air, and the burning gases are not too quickly cooled.

This appliance illustrates the great importance of selecting an orifice of correct size for each appliance and each gas supply. If too large an orifice is used, an excessive amount of gas is delivered and the liberation of carbon monoxide results. If too small an orifice is used, the supply of gas will not be sufficient to do the desired work

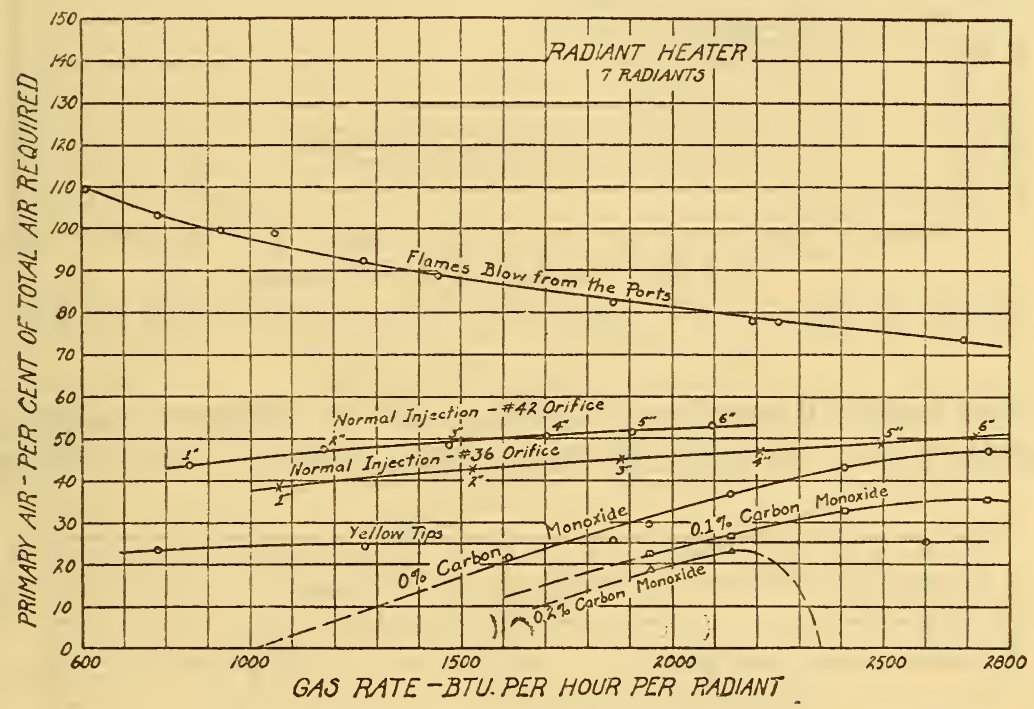

FIG. 8.-Performance of radiant heater No. \&

and, because the "air-gas ratio" increases as the size of the orifice is decreased, trouble from flash back or blowing may be encountered.

The importance of choosing an orifice of correct size is further indicated by Figure 8, which represents tests upon a heater which, as normally operated, with a No. 42 orifice does not approach a condition of incomplete combustion, flash back, blowing, or yellow tips. The danger of using too large an orifice is shown by the curve marked "normal injection No. 36 orifice." The No. 36 orifice not only gives an excessive amount of gas at the average city pressure, but the primary air injection is lowered so that the factor of safety is greatly reduced.

Figure 9 shows the results obtained with a heater which proved to be remarkably safe from any danger of incomplete combustion. Indeed, no carbon monoxide was found under any condition of test, 
and in those represented by the lowest (dotted) curre of the figure the appliance was burning with a yellow flame. The reason for this

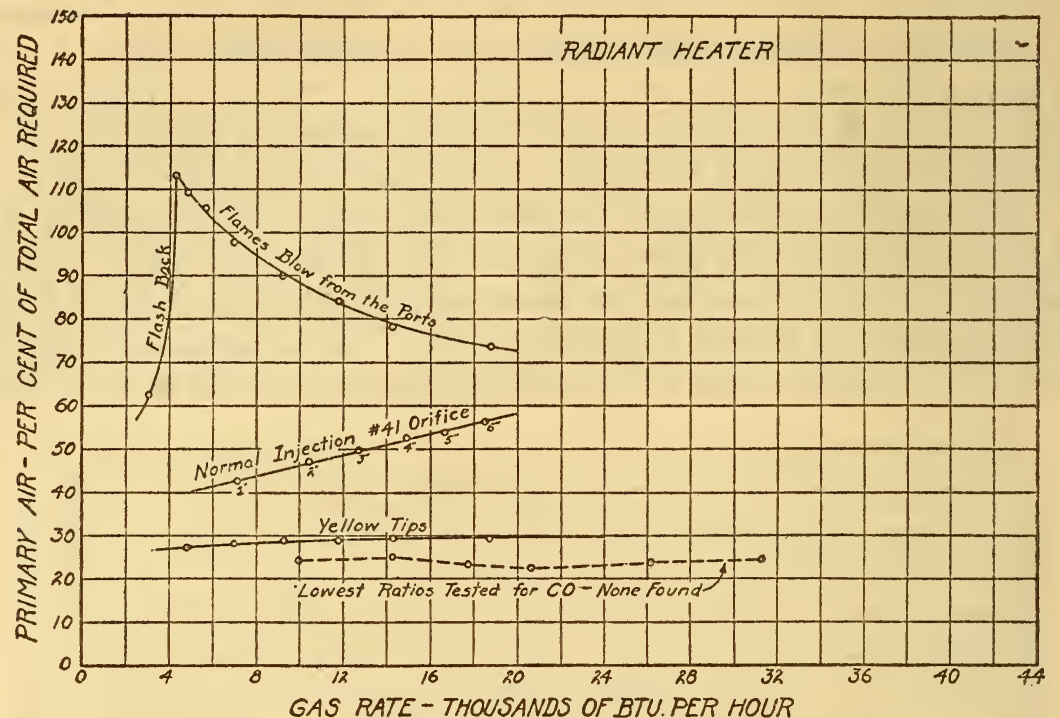

FIG. 9.-Performance of a radiant heater (No. 3) which burned the gas completely under all test conditions

is that under all conditions the flame had an abundant supply of secondary air. As normally operated this appliance was safe from

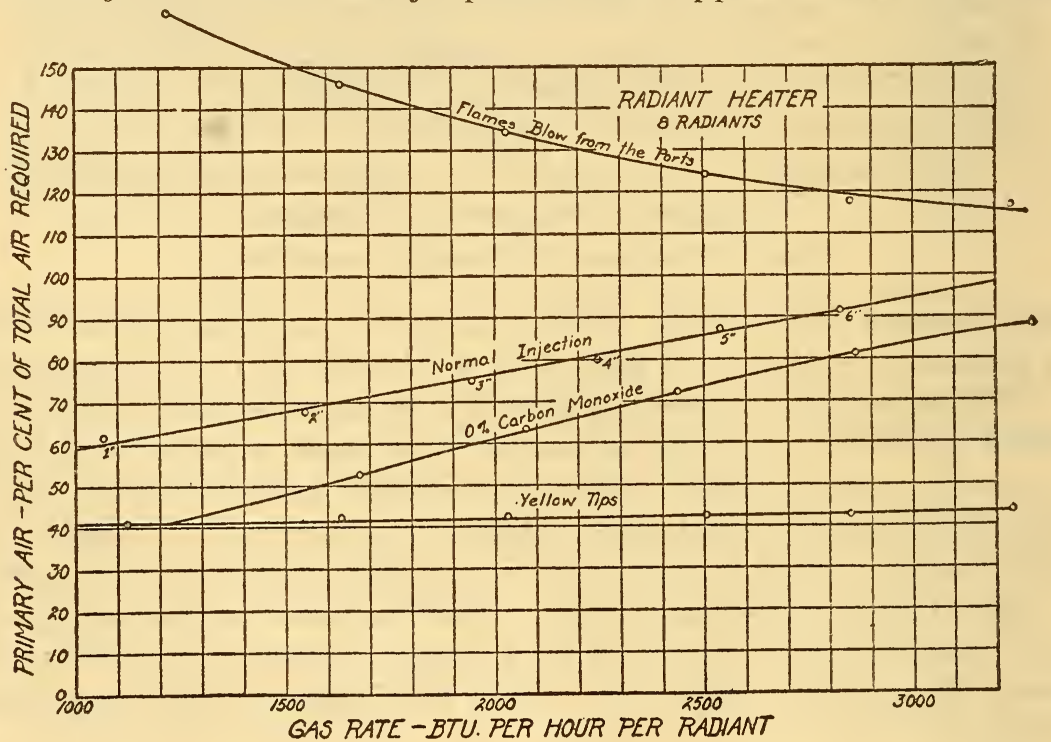

Fig. 10.-Performance of radiant heater No. 4

flash back, blowing out of the flames, or carbon deposition, as well as from the liberation of carbon monoxide. 
The curves shown in Figure 10 were obtained from a heater which was likewise free from flash back, blowing, or yellow tips. Carbon monoxide was produced in the forced tests, but only under conditions represented by points below the normal injection curve. This appliance, therefore, burns the gas completely when normally operated. The manufacturer of this radiant heater has on the market several other sizes differing only in the number of burners and radiants supplied. Since these appliances are each made up of a certain number of duplicate parts, it is necessary to test only one size. If the heat supplied is expressed in terms of heat units per radiant, the curves representing the results should be the same for an appliance with any number of radiants. This is the reason for giving the

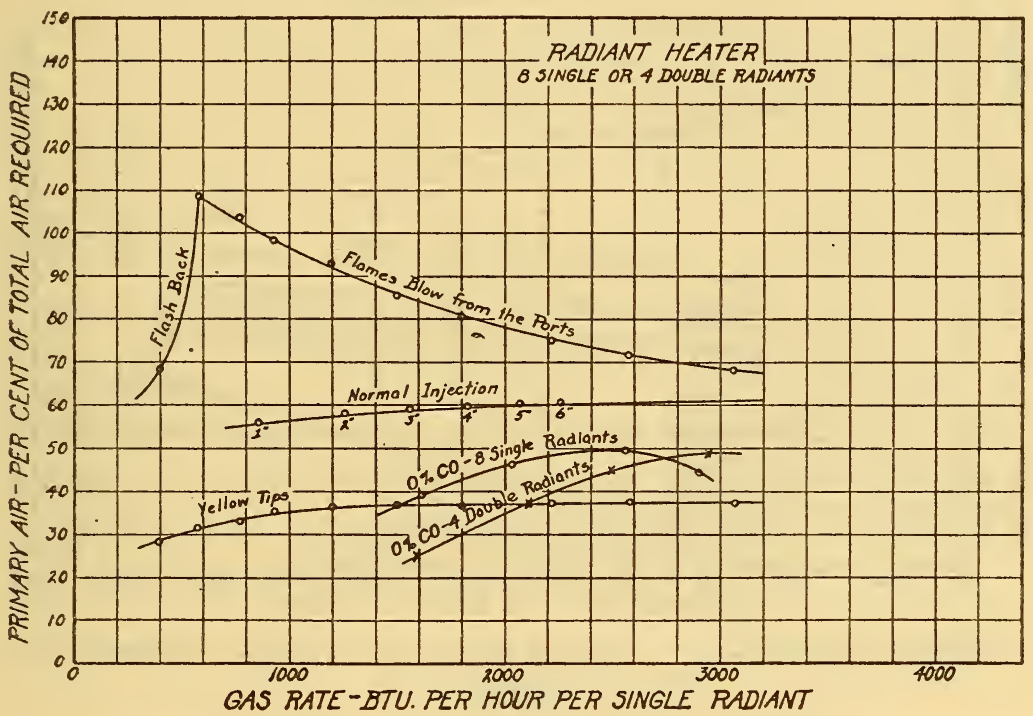

FIG. 11.-Performance of radiant heater No. 5

result in terms of heat per radiant instead of the heat delivered to the appliance as a whole.

Some other manufacturers make heaters in which burners of different sizes supply different numbers of identical radiants. In such a case it is necessary to test each model because the characteristics of the burner may vary with the number of radiants supplied.

Figure 11 represents the tests made upon a radiant heater interchangeably supplied with eight single or four double radiants. From the curves shown it may be seen that combustion was complete in the double radiants when using less primary air than was necessary with the single radiants. The use of the double radiants eliminated eight side walls; the space occupied by the walls became available for combustion and the flow of secondary air. 
Figure 12 was obtained from a radiant heater which was equipped with an adjustable air shutter. With the air shutter wide open, the flames blew away from the ports when the burner was first lighted. In order to overcome this, the shutter was closed slightly with a consequent reduction in the primary air injection. With this setting flash back resulted when the gas cock was suddenly turned off, so that a further closing of the air shutter was necessary. But even with this setting the air injection was well above the 0 per cent carbon monoxide curre, showing that the heater does not produce carbon monoxide if properly adjusted.

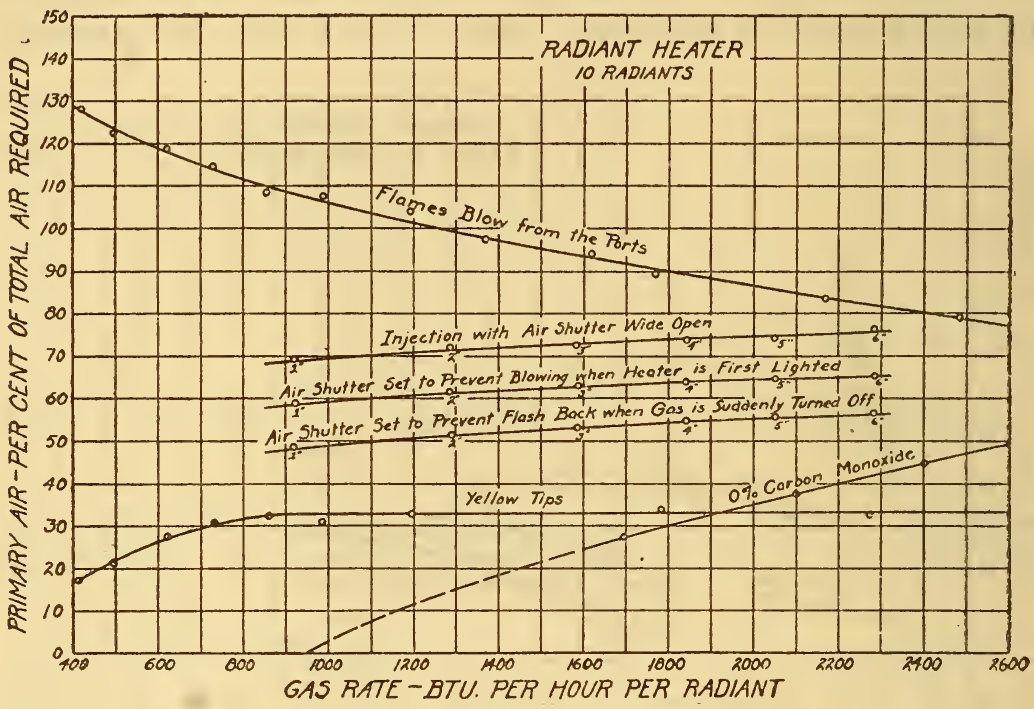

FIG. 12.-Performance of a radiant heater (No. 6) with adjustable air shutter

The appnances thus far discussed (figs. 7 to 12) are all safe as supplied by the manufacturer, or are easily rendered safe by simple changes or adjustments. The heaters represented by Figures 13 to 15 are dangerous, and their faults are not so easily remedied. Figure 13 shows curves obtained from a radiant heater equipped with multiple grid burners and mixing tubes which do not give satisfactory results. Two sets of burners were used in testing this heater, one having a total port area of 1.50 square inches and the other 1.35 square inches; those having the larger port area gave the better injection.

In order to make this appliance safe for use with Washington gas, some redesigning is necessary. Merely changing to a smaller orifice probably would not be satisfactory, because the reduction in size necessary to permit complete combustion would too greatly 
reduce the amount of heat available from the appliance. Even a change in the burner construction which would increase primary air enough to render the appliance safe from incomplete combustion. would bring it dangerously near to blowing out. The burners could well have a larger port area, which would increase the amount of primary air and raise the ratio at which the flames blow out; but the biggest improvement could probably be made by increasing the combustion space and providing better circulation of secondary air, thereby lowering the 0 per cent carbon monoxide curve.

Figure 14 represents the results of tests upon a radiant heater which failed because of an improperly designed burner. The injection curves obtained with two different orifices are shown. With

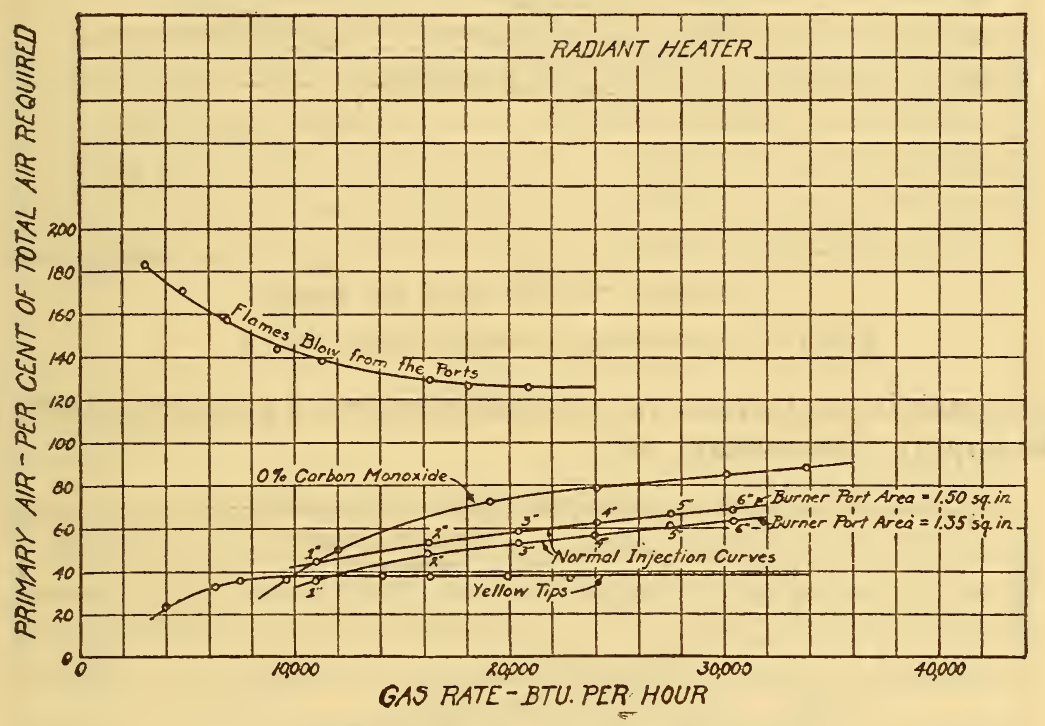

Fig. 13.-Performance of radiant heater No. 7

the No. 40 orifice a loud screaming noise was produced at pressures over 5 inches, and carbon monoxide was formed at pressures over 3 inches. A smaller orifice would give a higher percentage of primary air and prevent the liberation of carbon monoxide, but it would cause the screaming noise over a still greater range of pressures. A larger orifice, such as No. 36, avoids the noise, but it can not be used because the gas rate is excessive and the gas is not completely burned at the average city pressure.

Figure 15 was obtained from a radiant heater equipped with an air shutter. With the two orifices tried it produced carbon monoxide under all possible conditions of adjustment. In this case, as in that of the appliance represented by Figure 13, there is hardly margin enough between the conditions producing incomplete combustion 
and the blowing out of the flames to permit satisfactory results to be obtained merely by modifying the burner. The only remedy in this

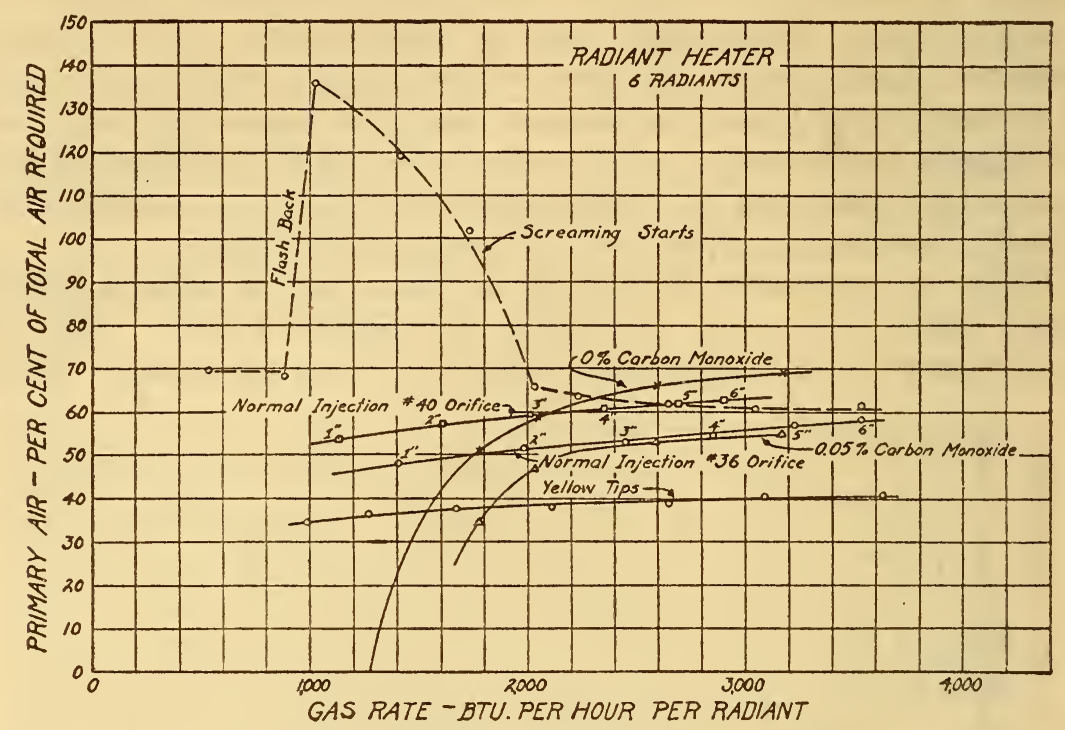

Fig. 14.-Performance of radiant heater No. 8

case must be an increase in combustion space or an improrement in the supply of secondary air.

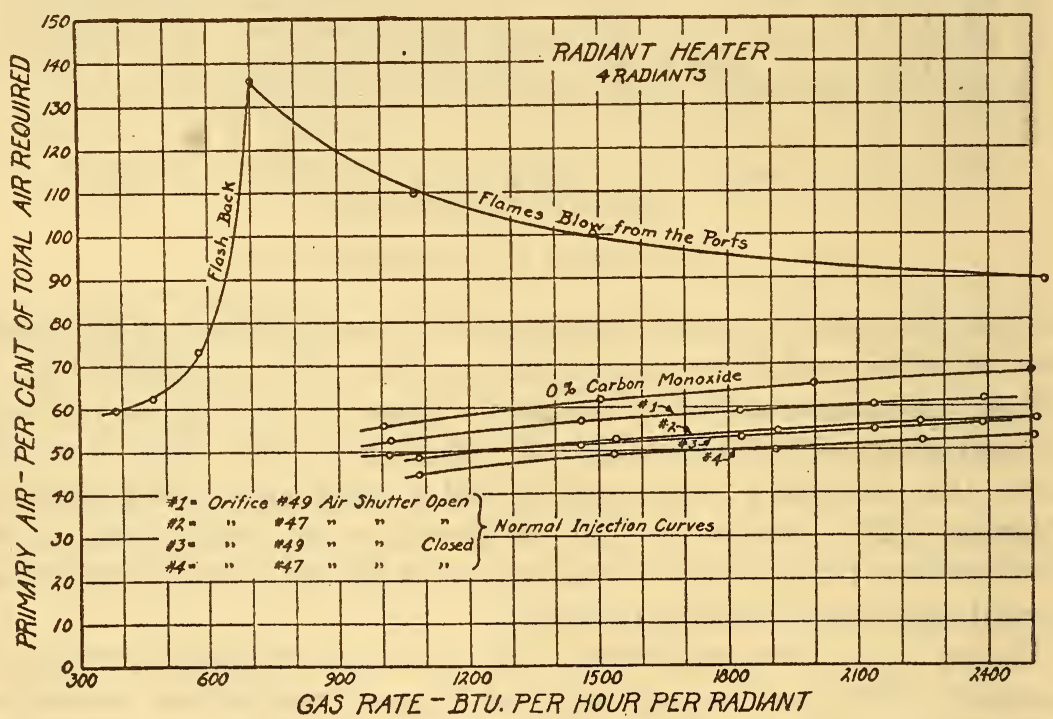

Fig. 15.-Performance of radiant heater No. 9

It is an interesting fact that no feature of construction which can be isolated served to distinguish the safe appliances from the unsafe 
ones; nor could their character be recognized by the appearance of the flame or any other characteristic except the actual composition of the products of combustion. The appliances may be divided into a group of five which completely burned the gas supplied to them under Washington conditions and a group of four which did not. In both groups were appliances with grid ports and appliances with drilled ports; appliances in which a single orifice, mixing tube, and burner supplied all the radiants; and others in which there was an orifice and mixing tube for each radiant or pair of radiants; appliances with air shutters and without, etc. One of the best heaters, as far as combustion is concerned, had a burner cheaply built of light sheet metal of doubtful strength and durability; one of the worst

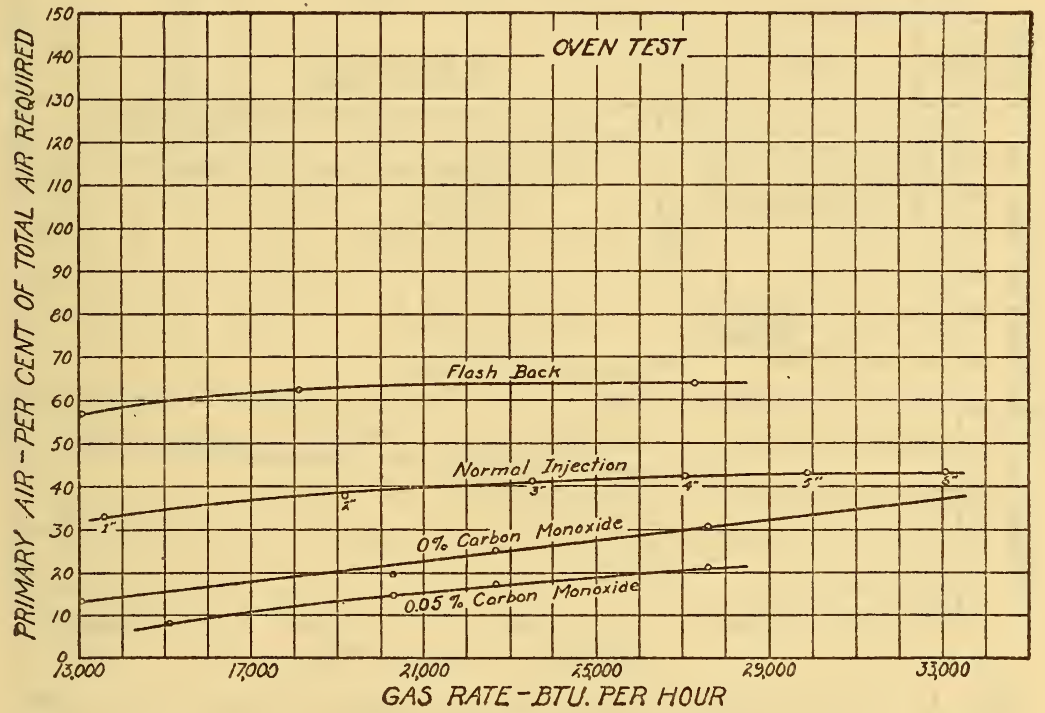

FIG. 16.-Performance of a well designed and adjusted oven

was strongly built of the best materials and beautifully machined throughout. Even such important single characteristics as primary air injection give little indication of safety. All four of the appliances that produced carbon monoxide under normal operation introduced more primary air than the heater that could not be made to produce carbon monoxide eren under the forced tests.

The next three charts (figs. 16, 17, and 18) show curves obtained from three very different gas-range orens. Figure 16 shows a welldesigned oren in which no incomplete combustion occurred when normally operated.

Figure 17 was obtained from an oren in which combustion was incomplete at low gas rates only. A baffle was placed directly over the burners and was so close that the flames impinged against it. 
When the gas was low, the amount of heat conducted away by this baffle cooled the gas below the reacting temperature before combustion was complete. When the gas rate was increased above 20,600 B. t. u. per hour, the amount of heat lost to the baffle did not affect the temperature of the gases enough to prevent their complete reaction. The supply of secondary air to the flame was also materially increased at the higher rates by increased thermal convection. This oven could probably be made satisfactory at all rates by increasing the distance between the burners and the baffle. The effect of a change of burner temperature upon the blow-off and flash-back curves is also shown on this chart.

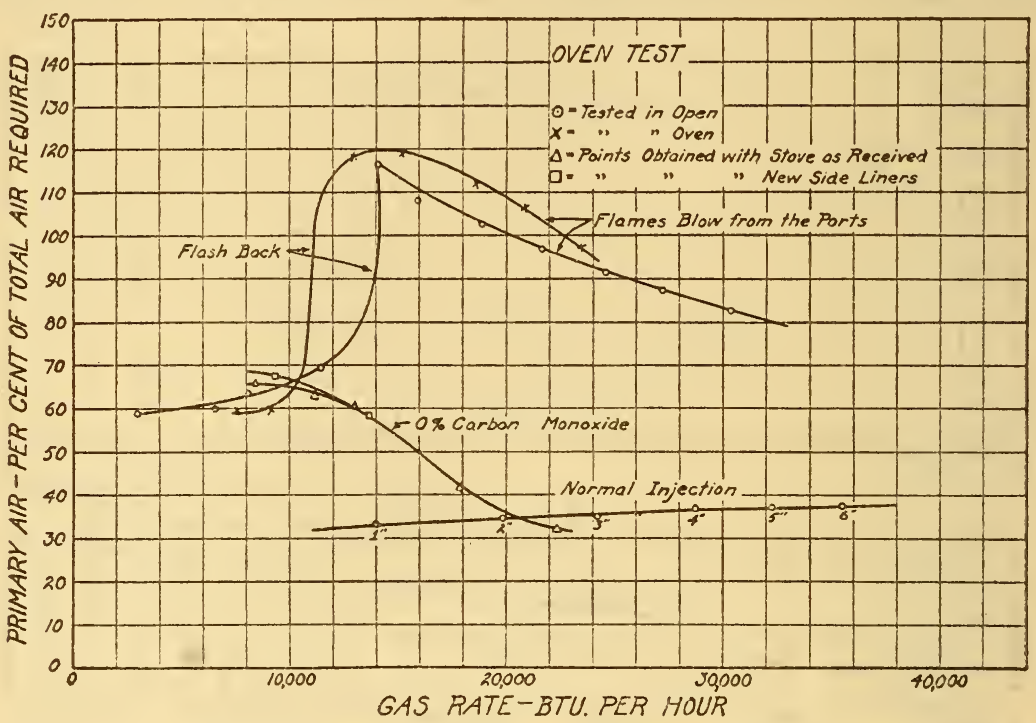

Fig. 17.-Performance of an oven in which flames impinge upon a baffle plate

Figure 18 is from an oren which produced large quantities of carbon monoxide at all useful gas rates; in this case a ring burner of unusual design gave perfect combustion until the pressure above the burner became higher than that below the burner, and the flow through the open center of the ring was downward instead of upward.

Figure 19 represents the characteristic performance of a good burner under a grate cooking top. The tests were made with a large kettle of cold water above the burner.

The assistance which may be rendered to a manufacturer as a result of tests of this kind is well illustrated by Figure 20. The appliance used in this test was a two-burner hot plate with ring burners. The curves show that with these burners large quantities of carbon monoxide were produced at all pressures above $1 / 2$ inch, 
which is not a practicable working pressure. The steepness of the 0 per cent carbon monoxide curve indicates that the flame volume

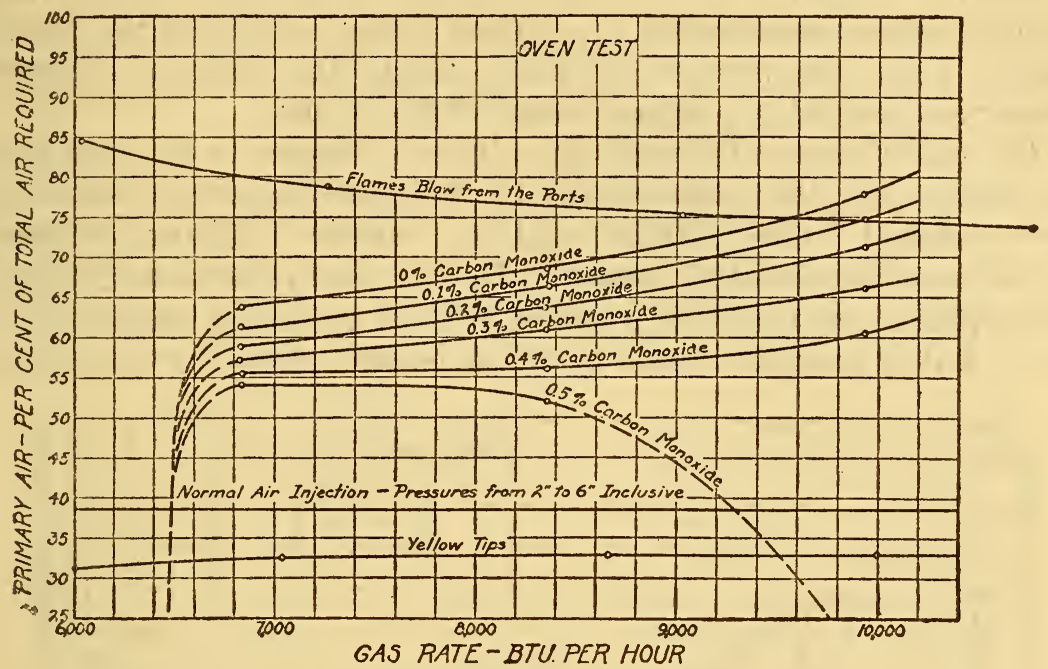

Fig. 18.-Performance of an oven having improper circulation of air about burner

was too great for the space in which it was required to burn, and also that the flames were not getting the secondary air required for

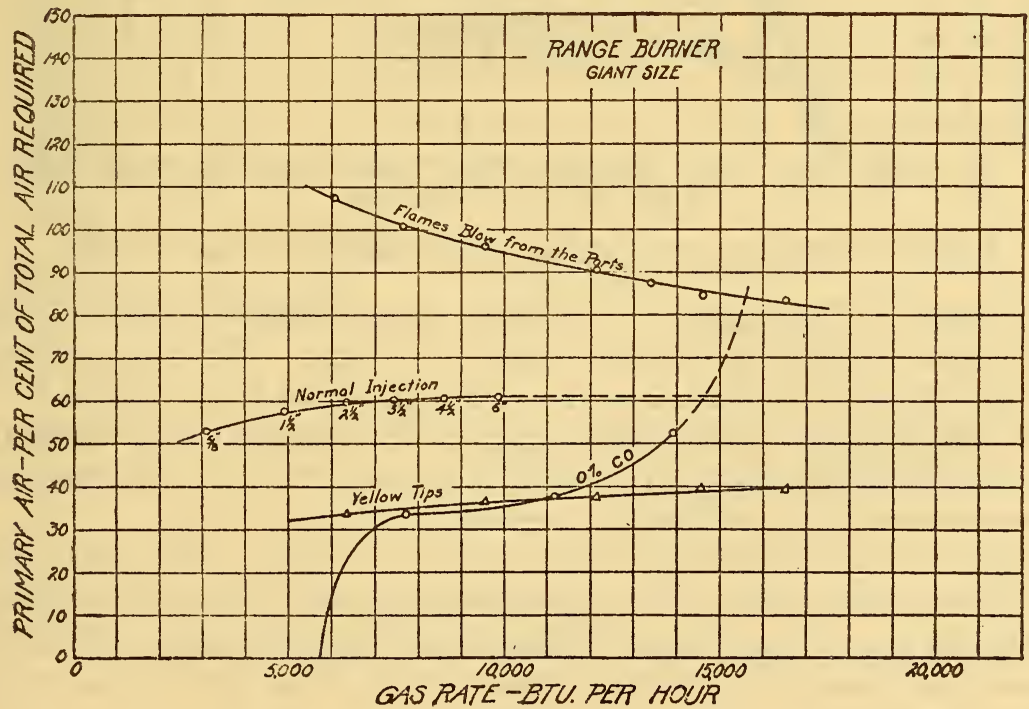

FIG. 19.-Typical performance of a good top burner

complete combustion; the flame was being smothered. As can be seen from the pressures marked on the normal injection curve for 
the ring burner, the orifices were too large. The maker of this appliance was advised to use an orifice which would give about $21,000 \mathrm{~B}$. t. u. per hour at 4-inch pressure; to change from the ring to star burners, because this type allows better aeration of the flame; and to lower the burners $1 / 4$ inch, making the distance between burner and utensil $11 / 2$ inches instead of $11 / 4$ inches.

The manufacturer followed the advice in respect to the first two suggestions, and the result is shown by the 0 per cent carbon monoxide curve marked "curve obtained with star burners-distance between utensil and burner $=11 / 4$ inches." It was then possible to operate the appliance up to 4-inch pressure without producing carbon monoxide, but it was still unsafe to use at 6 -inch pressure, which is the

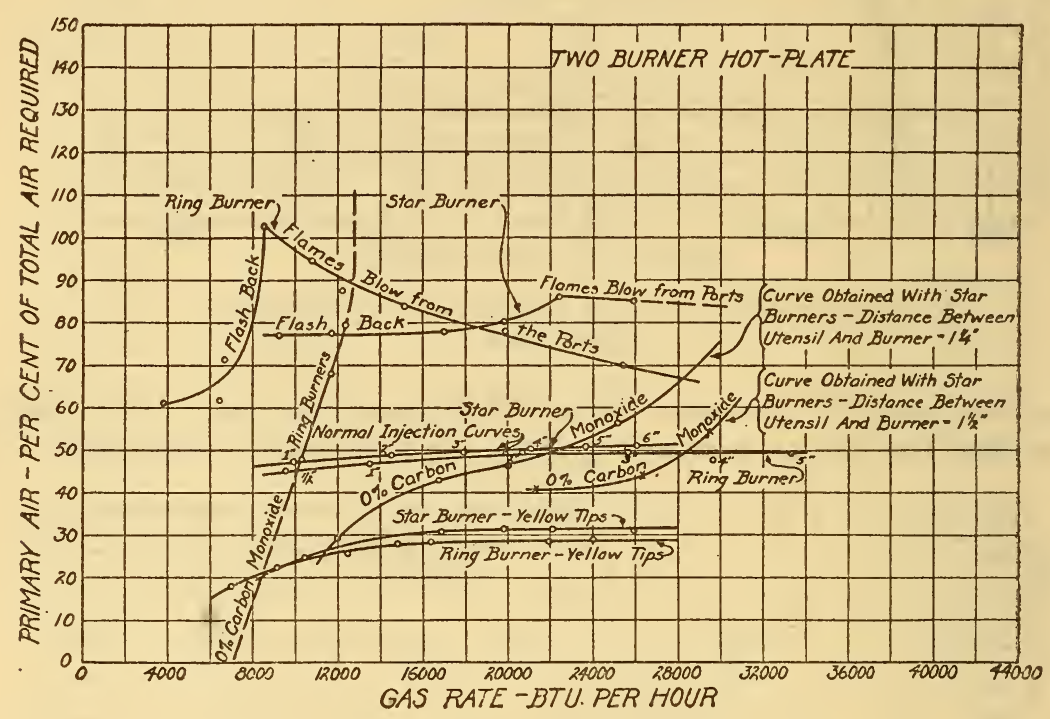

Fig. 20.-Performance of a hot plate showing effect of changes of design

legal limit in Washington. The third carbon monoxide curve shows the effect of lowering the star burners $1 / 4$ inch. With this change the appliance gave satisfactory results up to about 7-inch pressure.

It was therefore possible from one set of tests and a knowledge of the appliance construction to specify quite accurately the changes necessary to insure satisfactory service.

Figure 21 was obtained from a solid-top stove. Here again the steepness of the 0 per cent carbon monoxide curve shows that above a definite gas rate the flame volume is too great for the combustion space, and smothering of the flame results from the exclusion of secondary air.

Figures 22 to 25 all represent tests made on water heaters. Figure 22 illustrates the appearance of the curves from a well-designed heater having a properly designed burner correctly placed with 
respect to the coils, plenty of combustion space, and adequate passages for air and products of combustion, which insure a good

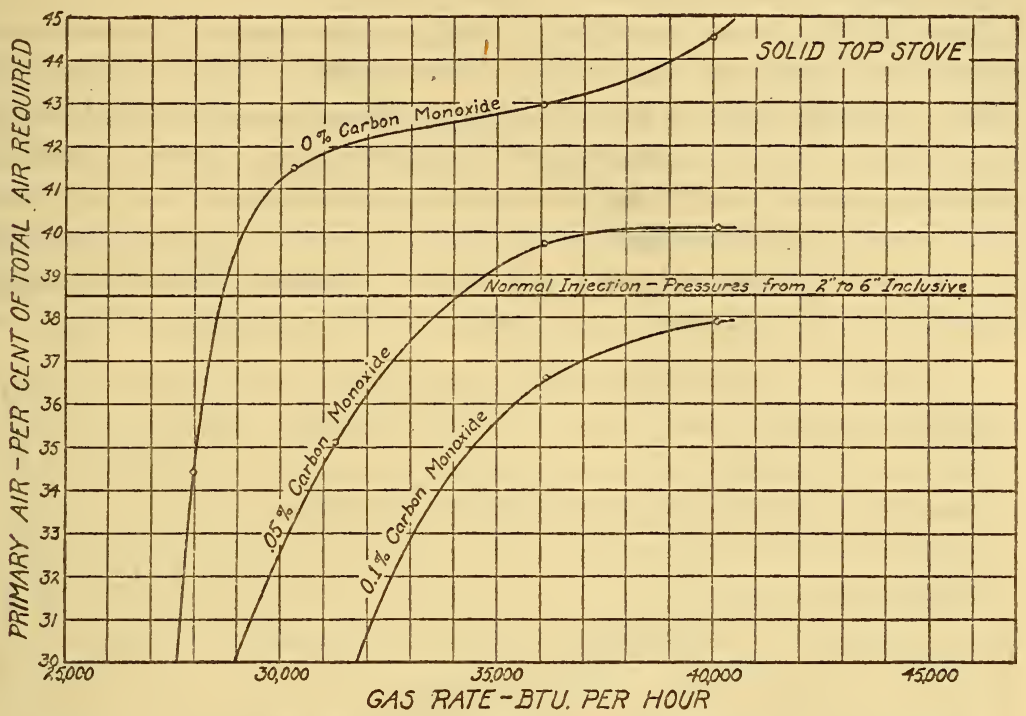

FIG. 21.-Limits of complete combustion in one range with solid top

supply of secondary air. The orifice supplied with this heater was a No. 30 , but in order to determine how large a gas rate could be

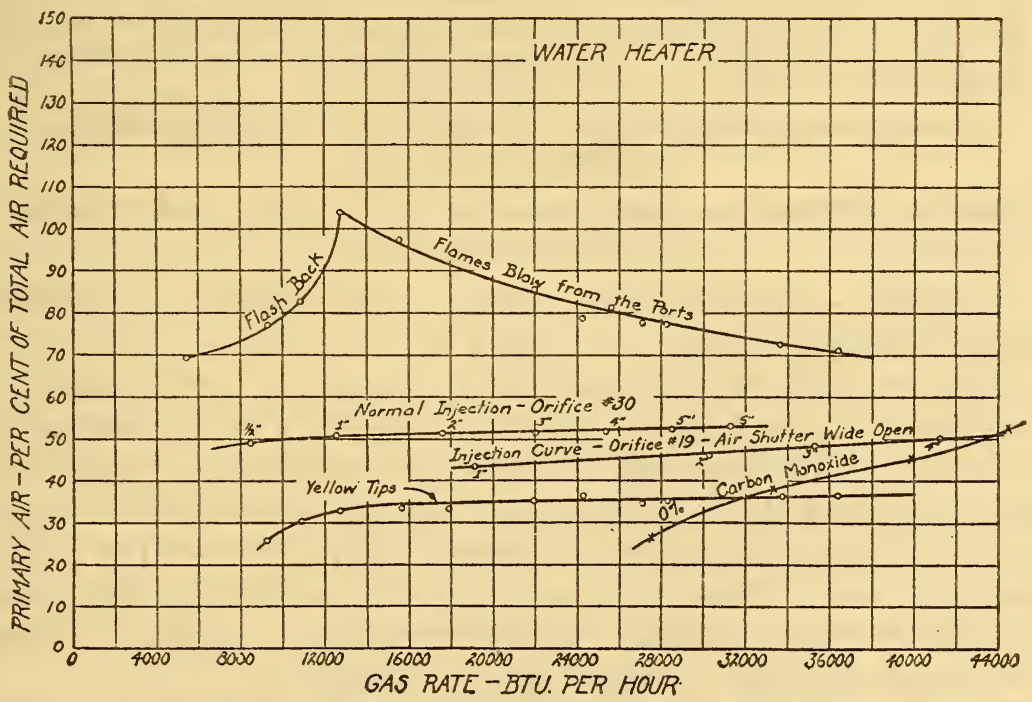

Fig. 22.-Performance of a typical water heater of good design

used without producing incomplete combustion a No. 19 was tried, and it was found that a rate of $44,000 \mathrm{~B}$. t. u. per hour could 
be supplied before a trace of carbon monoxide was formed. This, of course, is much in excess of the amount of gas needed for heating the quantity of water supplied by this heater.

Figure 23 illustrates the effect upon the operation of a water heater of merely changing the size of the burner ports. The curves marked $B$ were obtained with a burner having 56 ports and drilled with a No. 26 drill. No carbon monoxide was produced at normal operating conditions, but trouble from flash back was encountered. By decreasing the size of the ports to a No. 35 drill flash back at normal operating pressures was eliminated, and the factor of safety from incomplete combustion was increased, as shown by the lowering of the 0 per

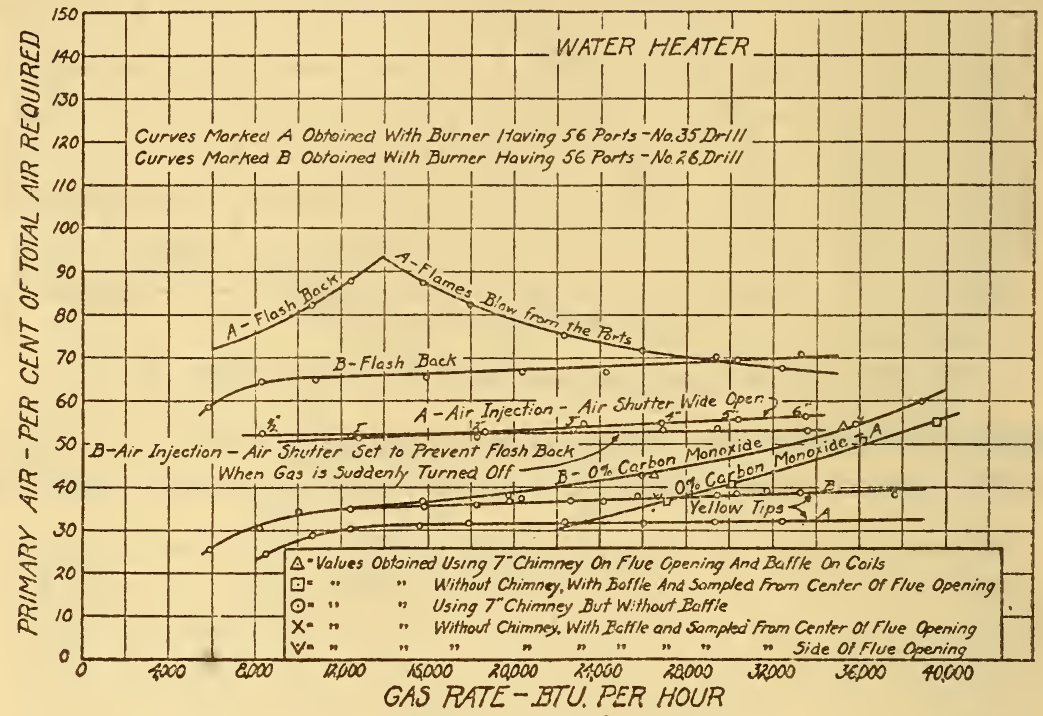

FIG. 23.-Performance of water heater No. 2 showing the efject of several changes of construction

cent carbon monoxide curve. (The curves showing the results obtained with this burner are marked $A$.)

It was of interest to see how a baffle on the coils of the heater, or the slight change of draft known to be caused by a 7-inch chimney on the outlet, would affect the combustion. Accordingly, tests were made with and without the baffle and with and without the chimney, and it was found that neither affected the position of the carbon monoxide curve. These tests were all made when using the burner with No. 26 ports, and their results are shown by points of various types which are fully explained on the diagram.

Tests were also made when using burner $A$ to determine if the products of combustion were uniform over the entire cross section of the flue opening. They were found to be so, as shown by points marked by squares and $V$. 
Figure 24 shows the curves from another water heater with a poorly designed burner. The fact that flash back occurred in the forced tests at all working pressures shows that the ports of the burner are too large. Decreasing their size would eliminate flashback trouble. The design of the burner did not permit the flames in the center to properly aerate, and the burner was placed too close to the water coils. By lowering the burner and decreasing the size of the ports this appliance could be made safe over the normal range of operation. As it is now, carbon monoxide is produced at all pressures over $5 \frac{1}{4}$ inches.

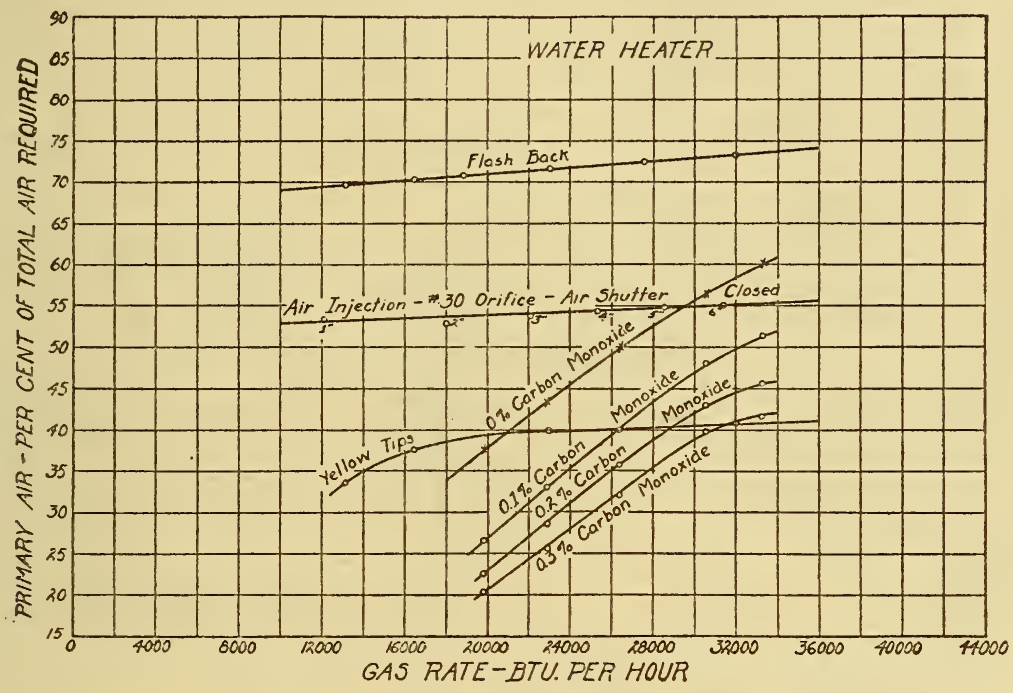

FIG. 24.-Performance of water heater No. 3

The last chart (fig. 25) was obtained from a water heater which had a well-designed burner, ample combustion space, but insufficient flue passages for the products of combustion to escape. This appliance will burn gas at a rate of $23,700 \mathrm{~B}$. t. u. per hour without a trace of incomplete combustion. Under this condition practically all the oxygen in the air entering the appliance is used. Any increase in the amount of gas burned, therefore, results in the formation of large quantities of carbon monoxide simply because not enough oxygen to burn so much gas is contained in the secondary air drawn through the appliance by conrection. The internal structure of the heater is such that the products of combustion pass upward in two quite distinct channels and do not mix perfectly before reaching the vent. The composition of the flue gas was, therefore, different on the two sides of the rent; the effect of this difference is shown by the different 0 per cent carbon monoxide curves in the figure. As this appliance failed because it did not get sufficient secondary air, 
anything that increases the draft through the shell improves the operation. With this appliance, therefore, the 7-inch chimney had a marked effect.

Because appliances are not always connected to flues and because the draft in a chimney is not always positive, heaters should not be dependent on the action of the flue to give complete combustion. This water heater should be so designed that there is an adequate supply of secondary air without the additional convection produced by a flue.

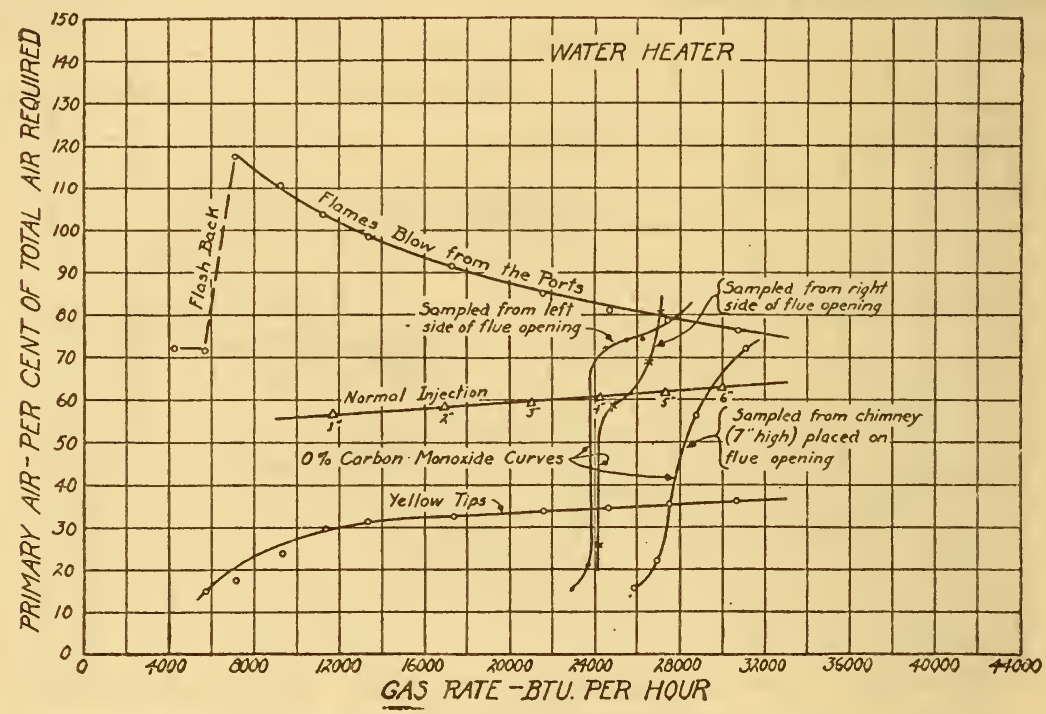

FIG. 25.-Performance of water heater with insufficient druft

\section{SUMMARY}

A method is described for making and graphically representing tests of gas appliances which show the margin of safety of an appliance from flash back, blowing out of flames, the deposition of carbon, and incomplete combustion which results in the liberation of carbon monoxide. The results of tests upon a variety of appliances are shown. It is pointed out that the characteristics of an appliance can not be accurately judged from appearances even while the appliance is in use.

Washingtor, July 6, 1925. 